\title{
PRAGMATIC TRANSFER IN REQUEST REALIZATIONS
}

\author{
Indawan Syahri \\ Universitas Muhammadiyah Palembang, Palembang \\ A. Effendi Kadarisman \\ Universitas Negeri Malang, Malang
}

\begin{abstract}
This study investigates the pragmatic transfer in English request realizations made by EFL learners, i.e. the proficient learners. The subjects were students of an English Study Program who obtained TOEFL-like scores of at least 450 . The data were collected by means of DCT-questionnaires and Role-plays. The results show that the subjects realize requests in the form of external modifications more frequently. Most of them embed their requests with supportive moves dominantly. They enfold the acts with the moves before, after or in both positions. Of the three positions, they mostly insert the moves initial position, i.e., through inductive patterns. This is due to pragmatic transfer.
\end{abstract}

Key words: request realizations, pragmatic transfer, request modifications.

It is assumed that when a speaker ( $\mathrm{S}$ ) conveys messages he gets involved in both language and communicative acts. The $\mathrm{S}$ is obviously doing things with words when he talks. The acts realized are based on the S's intentions - what he wants others to believe, accept, or do. The utterance, "It's very hot in here" does not only describe a state of affairs in the world or a truth value, but it is also used for requesting others to open the window or turn on the fan or air conditioner when it, for instance, is uttered by a teacher in an uncomfortable room. If the hearer $(\mathrm{H})$ only considered the explicit meaning of the utterance, misunderstanding would occur and the communication would possibly breakdown. In other words, the intended meanings are not always conveyed within the sentence level. In fact, the Ss often utter expressions that mean more or beyond what are said.

Meanings conveyed through speech act realizations are apparently influenced by the context in which cultural aspects are embedded. Utterances 
produced are not made in a cultural vacuum (Thompson, 2003:83). Each $\mathrm{S}$ tends to bring his own set of assumptions to what is happening and his cultural background that influence the way he perceives something. Moreover, in the context of a learner's language or Interlanguage (IL), pragmatic or sociolinguistic transfer potentially occurs due to cultural differences. That is, the transfer occurs due to the norms derived from their native cultures. For instance, Indonesian learners often transfer the non-acceptance strategy using 'no' when responding to English compliments which they usually use in bahasa Indonesia. In contrast, native speakers (NSs) do not; instead they use acceptance strategy using 'yes' and 'thank you'.

Concerning how learners use an L2/FL, particularly how they do speech act(s) in their communication, many pragmatic researchers have focused their studies on speech act realizations with the IL perspectives as the main concerns. IL pragmatics deals with non-native speakers' use and acquisition of linguistic action patterns in a second language (Kasper \& BlumKulka, 1993:3). It is commonly known that one of the factors causing the illformed or deviant language production in $\mathrm{L} 2 / \mathrm{FL}$ is interference or $\mathrm{L} 1$ transfer. The same case also occurs in IL pragmatics, also known as pragmatic transfer or sociolinguistic transfer, i.e., "the use of rules of speaking from one's own native speech community when interacting with members of the host speech community or simply speaking or writing a second language" (Wolfson, 1989:141). Again, most of IL pragmatic studies have investigated language use. They typically examined the performance of language learners at a particular point in development and compared it with NSs on a single speech act or a small set of speech acts in order to identify the distinction between the groups of NSs and of the learners or nonnative speakers (NNSs). The studies have shown that there are distinctions between learners and native speakers' enactment of speech acts in the degree of directness, mitigation, and maximization (Fraech \& Kasper, 1989; Suh, 1999; Yu, 1999; Hassal, 2001).

This study attempts to present the enactment of language learners' speech acts which specifies one type of the realizations, i.e. the acts of requesting. It tries to answer the question "How does the pragmatic transfer occur in the acts of requesting in English by the EFL learners?" It describes how the transfer of native-culture norms occurs in their speech act realizations, especially in request realizations. The present study is expected to contribute to the field of English Language Teaching (ELT) in Indonesian context, since it describes culture-specific acts of requesting done by Indonesian learners of English (ILE). 


\section{METHODOLOGY}

For this purpose, the study focused on the acts realized by ILE who had good English proficiency. Accordingly, the subjects recruited for the study were undergraduate students of an English Study Program who had TOEFL-like scores of at least 450. They were the students of Sriwijaya University (a state university located in Indralaya, South Sumatra Province, Indonesia). There were 68 students selected as the subjects of the study: 17 third-semester students, 26 fifth-semester students, and 25 seventh-semester students.

There were two types of instruments used in collecting data. The first instrument was the DCT questionnaires which consisted of a number of certain situations and were followed by blank spaces on which the subjects were asked to provide an appropriate linguistic form of requesting acts - as though they were the speakers in real-life interactions, for instance:

Situation 1: You are preparing for a mid-term examination which is scheduled tomorrow. It's about 9 p.m. A new neighbor about your age whom you do not already know is playing music very loudly. So you cannot concentrate on studying. You want this neighbor to turn down the music. What would you say to get the neighbor to do this favor?

The DCT descriptions explicitly told the subjects about the roles that they play in such situations. The situational variables dealing with social distance (familiarity) and social power (dominance) were embedded. Based on the situations and roles described, the subjects were asked to produce requests in the blank spaces provided (see Appendix 1).

As for the second instrument, out of 68 subjects, 36 (26 fifth-semester and 10 seventh- semester students) were selected as the participants of the role-plays. They were asked to produce dialogues based on the scenarios written in the role-plays. The procedures were conducted very carefully to maintain continuous participation of all the participants. In order to prevent repeating other participants' utterances, the researcher put each scenario on a strip of paper and rolled the papers into coupons. They were given opportunities to take three or four coupons randomly and produce dialogues in front of the class with their fellow students. They practiced the role-plays in pairs. 
These stages were done several times in several meetings until every subject played at least 6 of the 10 scenarios provided (see Appendix 2). As a result, there were 203 dialogues that could be recorded and transcribed.

With respect to request modifications as the bases of categorization in the study, the modifications were classified into two main categories, that is, internal and external modifications (Blum-Kulka, 1989). The internal modification dealt with the mitigation and aggravation of the imposition on the Hs which are only dependent on the head acts of the requests, i.e., the utterances containing the acts of requesting. The head acts were in the form of words or phrases, and consisted of downgraders and upgraders.

1. Downgraders

a. Syntactic downgraders

1) Interrogative

Could you do the cleaning up?

2) Negation

Look, excuse me. I wonder if you wouldn't mind dropping me home.

3) Past Tense

I wanted to ask for a postponement.

4) Embedded 'if' clause

I would appreciate it if you left me alone.

b. Lexical/phrasal downgraders

1) Consultative devices (The speaker seeks to involve the hearer and bids for his/her cooperation.)

Do you think I could borrow your lecture notes from yesterday?

2) Understaters (The speaker minimizes the required action or object)

Could you tidy up a bit before I start?

3) Hedges (The speaker avoids specification regarding the request.)

It would really help if you did something about the kitchen.

4) Downtoner (The speaker modulates the impact of the request by signaling the possibility of noncompliance.)

Will you be able to perhaps drive me?

5) Politeness device 


\section{Upgraders}

Can I use your pen for a minute, please?

1) Intensifiers (The speaker over-represents the reality.) Clean up this mess, it's disgusting.

2) (The speaker explicitly expresses negative emotional attitudes.) You still haven't cleaned up that bloody mess!

\section{Chttp://carla.acad.umn.edu/speechacts/requests/strategies.html}

The external modification referred to "supporting moves," or other utterances which existed before or after the head acts. The supportive moves affected the context in which they were embedded, and thus indirectly modified the illocutionary force of the request. The following are the types of external modifications.

1) Checking on availability (The speaker checks if the precondition necessary for compliance holds true.)

Are you going in the direction of the town? And if so, is it possible to join you?

2) Getting a precommitment (The speaker attempts to obtain a precommital)

Will you do me a favor? Could you perhaps lend me your notes for a few days?

3) (By expressing exaggerated appreciation of the requestee's ability to comply with the request, the speaker lowers the imposition involved.)

You have the most beautiful handwriting I've ever seen! Would it be possible to borrow your notes for a few days?

4) (The speaker indicates awareness of a potential offence and thereby possible refusal.)

Excuse me, I hope you don't think I'm being forward, but is there any chance of a lift home?

5) Cost minimizer (The speaker indicates consideration of the imposition to the requestee involved in compliance with the request.)

Pardon me, but could you give a lift, if you're going my way, as I just missed the bus and there isn 't another one for an hour.

$<$ http://carla.acad.umn.edu/speechacts/requests/strategies.htmlì 


\section{RESULTS OF THE STUDY}

\section{Request Modifications}

It was found that the external modifications appeared more frequently than the internal modifications. There were $725(66 \%)$ of the 995 requests in DCT and 192 (95\%) of the requests in 203 dialogues in role-plays which were modified externally. The rests were modified internally, i.e., 243 (34\%) in DCT and 11 (5\%) in role-plays, as shown in Figure 1.

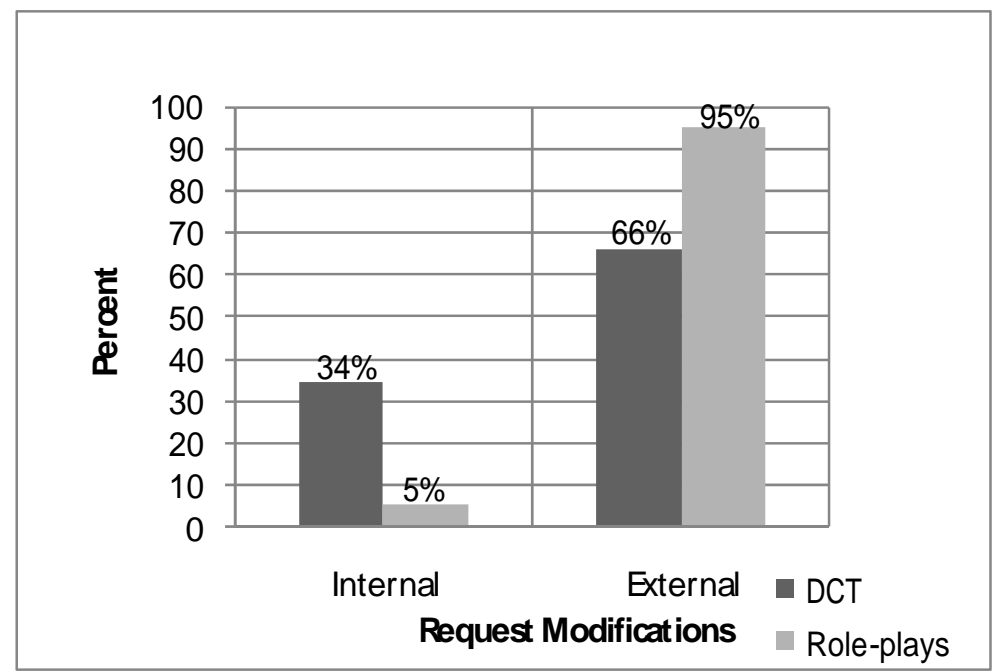

\section{Figure 1. Occurrences of Request Modifications}

The following are examples of requests they modified when responding to the situations in DCT questionnaires.

Situation 1: want a new neighbour to turn down the music.

(1) Turn down the music, please.

Situation 2: want to borrow a pen from a person

(2) Excuse me. Can I borrow one of your pens, please?

Situation 3: want to ask the lecturer to allow you to take a course.

(3) Excuse me, sir. I didn't know that your course requires a prerequisite course. But I'm really interested in taking your course. So, would you let me to study in and give me a chance to study in your course? 
Situation 4: want to ask an older person to open the door

(4) Excuse me sir, would you mind opening the door for me because my hands are so full. Thank you for your help, sir.

Situation 5: want to ask a nearby student to take a picture.

(5) Excuse me. Can you take a picture of us, please?

Situation 6: want to ask a lecture to reschedule the final exam.

(6) Excuse me, sir. Next Friday is my brother's wedding and it's a very unforgettable Moment for my family. Could you allow me to take the exam not on that day, sir?

Situation 7: want a fellow student to share the textbook

(7) I don't bring my textbook with me. So, do you mind I we see the textbook together?

Situation 8: want to borrow the handout from the lecturer.

(8) Excuse me, sir. I didn't come on last meeting because I was sick. Could lend me the textbook?

Situation 9: want the lecturer to extend the deadline of assignment.

(9) Excuse me, sir. Could you extend the deadline of the final paper because I don't think I will be able to submit the paper on time?

Situation 10: need to ask this fellow student to help you get ready for the exam.

(10) Excuse me. Would you mind helping to face the exam? I can't get several main ideas of the topic. I see that you understand more.

Situation 11: need to ask for the lecturer's permission to sit in.

(11) Excuse me, sir. Do you mind if I sit in your class to join with the class?

Situation 12: want to borrow a fellow student's notes. 
(12) Can I borrow your notes about last meeting topic? Because I think that I'm quite difficult to catch up with the class only with my notes.

Situation 13: ask the assistant to find a T shirt with a suitable size for you.

(13) I need an M size. Could you find it one for me, please?

Situation 14: want to a teenager to show an office in the city.

(14) Excuse me. Would you mind to let me know the way to this office?

Situation 15: need to ask someone to show you the principal's office.

(15) Excuse me. Could you tell me where the principal's office is?

\section{Internal Modifications}

The subjects inserted mitigating devices inside the head acts. They modified the requests internally and the clarity and imposition were dependent on the head acts themselves without other elements supporting the head acts as in examples (1), (2), (5), (11), (14) and (15). They used both syntactic downgraders, (i.e., interrogative) and lexical downgragers (i.e., politeness devices 'excuse me' and 'please'). The examples show that 'excuse me' and 'please' were considered important devices by the subjects to downgrade the imposition on the Hs.

Further, it was found only 11 dialogues in role-plays in which the subjects realized requests through internal modifications: 5 dialogues in Scenario 5 as in excerpt (16), 1 in Scenario 6 as in (17), and another 5 in Scenario 9 as in (18). The Ss modified their requests in the head acts without giving grounders. The following are examples of requests modified in the head acts.

Scenario 5: need someone to help you find the place.

(16) A: Excuse me /... Can you tell me where this place is?

B: Okay / just walk along the street / if you see / there is an intersection / you turn left.

A: Okay / thank you.

B: You're welcome. 
Scenario 6: want to see and consult with your advisor about the paper.

(17) A: Morning sir / - morning Mam.

B: Morning.

A: Would you please / check my SKRIPSI / I have completed?

B: Okay / let me take.

A: Thank you / Mam.

B: You're welcome.

Scenario 9: need to ask the shop assistance to let you try on s pair of shoes.

(18) A: Excuse me.

B: Yes / what can I do for you?

A: Want to try / eh / the pair of shoes.

B: Which one?

A: The black one.

B: Okay / I'll take it

Here it is.

A: Oh / thank you.

B: You're welcome.

Among the 11 internal modifications, the Ss modified 10 of their requests in the form of query preparatory in the way of checking the ability using can as in (16) and willingness using would as in (17). There was only one in the form of want statement as shown in (18). The mitigation was dependent on the head acts themselves without necessarily adding the head acts with other elements.

\section{External Modifications}

In external modifications, they might add their requests with supportive moves in initial position or before the head acts, after (postposition) the head acts or in both positions. It was obvious that the subjects in the DCT provided supportive moves in initial position before the head acts, $54 \%$ in DCT and 55\% in the role-plays of the requests. The others were in postposition, $38 \%$ after the head acts in the DCT and $22 \%$ in the role-plays; and in both positions - before and after the head acts, $8 \%$ in the DCT and $23 \%$ in the role-plays. The supportive moves in initial positions prevalently emerged in their externally modified requests (see Figure 2). 


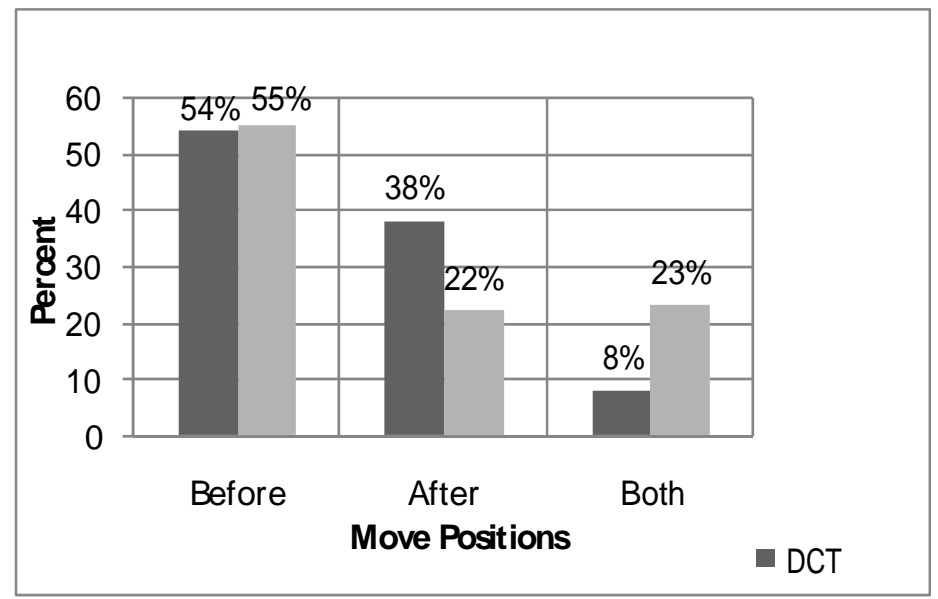

\section{Figure 2 Supportive Move Positions}

Furthermore, the Ss used supportive moves for various motives. For instance, by giving explications they could realize their requests as clearly as possible so that the Hs knew what they wanted to do as the compliance of the requests. By asking the H's willingness, as another example, the Ss mitigated the imposition on the Hs. Some Ss embedded more than one functions of supportive moves. They might add an utterance giving reasons and another utterance softening the request acts. The functions of supportive moves are classified into six categories, i.e., grounder, disarmer, getting a pre-commitment, checking on availability, cost-minimizer, and sweetener. It was found that the subjects embedded their requests with grounders most frequently, $66 \%$ in the DCT and 52\% in the role-plays, while other supportive moves were less frequently used as shown in Figure 3.

Grounders are the reasons embedded in the request utterances. The subjects added most of the head acts with several supportive moves. There were $66 \%$ in the DCT and 52\% in the role-plays showing that the subjects externally modified their requests by making use of grounders, reasons or explanations for realizing requesting acts, as in examples (3), (4), (6), (7), (8), (9), (10), (12), and (13). The following is also an example of how the $\mathrm{S}$ set grounders in his request realization. 


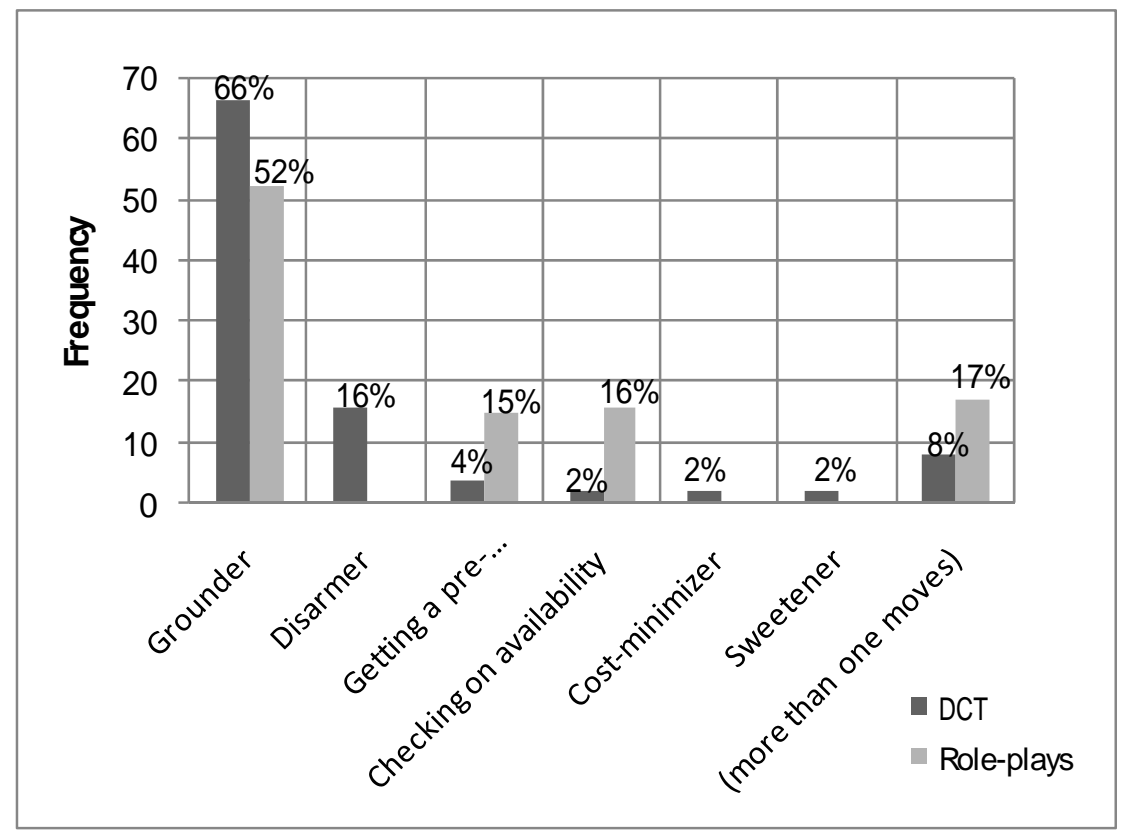

Figure 3 Frequency of Supportive Moves in DCT and Role-plays

Scenario 3: want the librarian to help you to find a book.

(19) A: Excuse me / MISS // I / have some difficulties in finding books / actually I need to find a book / the title is / HOW TO BE A PROFESSIONAL TEACHER / Can you help me / to find it?

B: Yes / because that book is in...

A: Yes / thank you.

Disarmer was also used by the subjects when realizing the requests. There were $16 \%$ in the DCT showing modified requests by adding disarmers. It indicates the subjects' awareness of a potential offense and thereby potential refusal.

Situation 3: want to ask the lecturer to allow you to take a course.

(20) Excuse me, sir. I want to take your class for this subject but I haven't got the prerequisite course, but I can guarantee that I'm able for this course as my previous experience. 
Furthermore, supportive moves were also modified by the Ss for getting pre-commitment from the Hs. There were $4 \%$ in the DCT and $15 \%$ in the role- plays showing supportive moves used by the subjects, as in the following examples.

Situation 4: want to ask an older person to open the door

(21) Excuse me, sir. Can I ask you for a favor? I need to open the door but as you can see my hands are full of things. Would you like to open it for me?

Scenario 3: want the librarian to help you out to find a book

(22) A: Excuse me // can you help me?

B: Okay / what can I do for you?

A: I want to find a book / about science // and I don't know where the place is / would you like to tell me / where is the place / - where the place is?

B: Okay / about science // you go ahead / and turn left / and after that / there is / the book is / you have to find a code / is / 304 / to find / the kind of / science book.

A: ... Thank you

B: ...You're welcome.

In examples (21) and (22), the Ss used "can you do me a favor?" and "can you help me?" to obtain the H's commitment that the $\mathrm{H}$ was or was not able to do the acts requested.

Checking availability is another type of supporting moves, which is used for checking whether the precondition necessary for compliance holds true. Some of the subjects (2\% in the DCT and $16 \%$ in the role-plays) embedded their requests with this type of supportive moves. They modified the supportive moves by means of several ways as shown by the following examples.

Situation 2: want to borrow a pen from a person

(23) Sorry, girl. Do you have another pen with you? If yes, could you please lend me one?

Scenario 7: ask your close friend to see the movie together with you.

(24) A: Hi ZEIN

B: Hi. 
A: Do you have spare time / at this weekend?

B: Weekend / weekend / weekend // yes / I think so.

A: I have two free tickets / eh / to the movie / for... JAMES BOND.

B: Oh / my God! / JAMES BOND / I really love it.

A: Yeah / Do you want to watch it / together with me?

B: eh / yes / get free tickets / okay?

A: Yes / of course // I / I got it from my friend.

B: Which show / - what time / we will watch the movie?

A: em / eh / Saturday on / 2:30.

B: 2:30 / Saturday 2:30 // Okay / eh / you pick me up?

A: I don't think so / because / your house is / very far from my house.

B: So / we have to... / I think.

A: At 1 / okay / but don't forget to call me before you go.

B: Okay / see you.

A: See you / bye-bye.

The supporting moves were used for knowing the availability of the Hs to do what was requested. Both "Do you have another pen with you?" in (23) and "do you have spare time [at] this weekend?" in (14) were uttered before the head acts were realized. Besides checking the availability, the moves were used to mitigate the imposition on the Hs.

Cost minimizer was used to indicate that the subjects tried to minimize imposition on the Hs who were expected to comply with the requests. In the DCT, there were $2 \%$ requests externally modified through a costminimizer as shown in the following example.

(25) Excuse me. May I borrow your pen? I need to note something and I forget to bring my pen. I'll give it back to you after I finish using it.

The subjects embedded their requests with utterances aiming to minimize the risk of doing the acts. The $\mathrm{S}$ added his request with "I'll give it back to you after I finish using it" in (25) to convince that the H would not risk losing his pen, or risk the delay of its return. It was apparently found that this motive appeared with other supportive moves, for instance, with grounders as presented in the previous examples.

The next motive why the subjects used supportive moves was to sweeten the requests; this is called sweetener. Sweeteners made up $2 \%$ of 
the requests in the DCT. The subjects used it in order the Hs felt happy and then ready to comply with the request acts.

(26) You are so excellent in this class! Would you like to help me get ready for the exam?

The supportive move in (26) was uttered to mitigate the requests. Hopefully, by preceding the requests with these utterances the Hs would feel appreciated before doing the acts.

The subjects apparently used not only one type of supportive moves, but also combined two or more moves in some request realizations. Some of them used these combinations, i.e., $8 \%$ in the DCT and $17 \%$ in the roleplays.

(27) Excuse me, sir. Can I ask you for a favor? I need to open the door but as you can see my hands are full of things. Would you like to open it for me?

(28) A: (knocking the door) Excuse me.

B: Yeah.

A: I am LENI.

B: Oh / yes.

A: I think / you are / a new comer in the apartment!

B: May be you're right.

A: Welcome to our apartment // what do you think?

B: It's good apartment.

A: Yes / of course // by the way / you enjoy the music very much / right?

B: Yes.

A: Because I hear the music very loud // so, if you don't mind / would you please / turn / turn it down? // because / tomorrow I will / have final exam/ so tonight I have to study.

B: Oh / I know / I am so sorry if I disturb you...

A: That's *okay*

B: *Thank you* / to remind me about that.

A: It's okay.

Example (27) shows that the $\mathrm{S}$ combined two types of supportive moves, i.e., getting a pre-commitment "Can I ask you for a favor?" and a 
grounder "my hands are full of things". While in (28) the S used a costminimizer and a sweetener simultaneously by uttering "welcome to our apartment," and then after some turns continued with the first grounder "Because I hear the music very loud // so, if you don't mind" before realizing the head act "would you please / turn / turn it down?" and finally followed by the second grounder "because / tomorrow I will / have final exam/ so tonight I have to study."

To sum up, the subjects of the research realized similar patterns of requests in the sense of the dominant frequency in modifying their requests across the situations in the DCT and scenarios in the role-plays. They tended to use external modification in their requests, especially in conventionally indirect strategies. They supported their indirectness by adding the head acts with supportive moves. They used grounders most frequently in both the DCT and the role-plays as their supportive moves. They put their supportive moves more frequently before the request acts than after, and also more frequently than both before and after the head acts.

\section{DISCUSSIONS AND INTERPRETATIONS: PRAGMATIC TRANS- FER}

The ILE modify their acts of requesting both internally and externally. They use external modifications extensively. They surround their head acts of requests with other utterances - the so-called supportive moves in which they mean to strengthen the rationales to realize such requests. Most of them insert the moves before they utter the request acts while some after the acts. Some even enfold their supportive moves before and after the acts. These phenomena lead us to infer that the ILE apply an inductive pattern in realizing communicative acts, especially in making requests. In addition, we can also say that they apply the cyclical pattern (termed by Kaplan, 1996), which is commonly used by natives of Asian languages, due to the fact of enclosing the supportive moves before the head acts and in both initial position and postposition.

Most of them embed the supportive moves in the form of grounders. They give reasons, explanations, or the rationales of realizing requests. For instance, the $\mathrm{S}$ tells some reasons to the $\mathrm{H}$ 'I want to take notes but I don't have a pen with me" before he utters "Can I borrow your pen?" This kind of moves clearly shows that the $\mathrm{S}$ wants the request to be fulfilled after the $\mathrm{H}$ knows the state of the $\mathrm{S}$. They add their request acts with grounders in their external modifications. In some cases they repeat the moves to emphasize the reasons, explanations, or rationales or even insert other supportive 
moves to achieve the Hs' comprehension of the request, hence reducing threat on Hs and hopefully making the requests meet with compliance.

Other types of supportive moves embedded are disarmer, getting precommitment, checking availability, cost minimizer, and sweetener. Each has its own function. Disarmer shows the requester's awareness of a potential offense that potentially results in refusal. It is conveyed by the subjects using piety expressions, for instances, "I'm sorry for bothering you" and "... but I think I can't finish and submit my final paper punctually" In fact, the ILE also use this kind of moves in some request realizations, especially when they admit others to comprehend not only the surface of the utterances, but also take a pity on the $\mathrm{S}$ up-dated conditions.

Next, getting pre-commitment and checking availability serve as elements to obtain and glance the preparatory conditions. They often implant the moves before the head acts. The former is used to ask the ability or willingness to hear or share the requests that are made such as "Can you help me?" or "Can I ask you for a favor?" The latter refers to checking availability on the Hs, which is essential for launching the head acts such as "Do you have another pen with you?" These supportive moves actually have similar functions, that it to say, to check and possibly shape the preparatory conditions which help the Ss to obtain compliance. The sequential flows of the supportive moves and head acts are rather vague when they are elicited through the DCT due to the absence of turn-takings, but show up clearly in the role-plays. The moves are responded directly by the Hs, and then the Ss continue with the head acts in relation to the responses to the moves in the role-plays.

In order to end the requests with compliance, the Ss minimize the cost to the Hs, such as by saying "I'll give it back to you after I finish using it" or "I promise to give it back to you soon" after uttering "Can you lend me your pen?" The examples show that they apply this principle to support the requests. It is assumed that if they minimize the cost to the $\mathrm{Hs}$, the requests will probably be fulfilled. The cost minimizer moves also furnish the request realizations. The Ss attempt to minimize the cost to Hs by giving some statements containing benefit or at least reducing the unexpected consequences if the Hs do the acts requested. The aim of the two supportive moves above is to minimize the cost to the Hs. The Hs usually do the acts due to the guarantees given; besides, they may feel uneasy if they refuse to do the acts requested by the Ss.

The last supportive move is sweetener. The Ss usually use this move to reflect the social function of language. Its motive is to maintain the interaction between the interlocutors. The principle of praising others is applied. In 
this case, the Ss attempt to give credits to the Hs' pluses, for instances, "You are the best lecturer I've ever known" and "You are so excellent in this class" These two examples are found in the corpus of the collected data. The subjects try to make the $\mathrm{H}$ feel good, and as a result easily comply with the requests.

Other pragmatic transfers were politeness motivated; they were the ways the subjects initiated the request realizations. Many of the them used 'Sorry' or 'I am sorry' instead of 'Excuse me' as the attention getters, whereas native speakers of English would never start a request by saying, "I'm sorry." In English, 'sorry' is commonly used to express sorrow, regret, or penitence (Merriam-Webster, 1985:1126), for instance, "I'm sorry to hear that" to express condolences. The following are the examples of requests using 'sorry' as polite attention getters.

(29) Sorry, I have to study for a mid-term examination tomorrow. So, can you turn down the music?

(30) I am sorry. May I borrow your pen, please?

The uses of 'sorry' here were inappropriate in the context in which the Ss did not mean to express sorrows or regrets. In fact, they transferred the term 'maaf' in Indonesian to their requests. The natives of Indonesian often used the term 'maaf' to avoid FTAs (termed by Brown \& Levinson, 1987) or at least to reduce the impositions to others when doing things with words. The subjects in this respect realized their requests in such a way in responding to the DCT-questionnaires. These kinds of construction were apparently found in every situation.

\section{CONCLUSIONS}

Speech act realizations are evidently culture-specific. The Indonesian learners of English who served as research subjects in the present study, while considered proficient enough in English, are apparently still influenced by their native culture-norms. In request realizations they mostly do some embedment by enfolding supportive moves before executing the head acts of requesting. This shows that they employ an inductive pattern and some even apply cyclical development, i.e., delaying the points to be requested. The use of 'sorry' and 'I'm sorry,' which is politeness motivated, are other examples of pragmatic transfer emerging in their request realiza- 
tions. This is truly culture-specific. Indonesian native speakers get accustomed to using 'sorry' in opening their conversations.

It is probably unproblematic when the requests are directed to other Indonesian interlocutors. But it is troublesome if the ILE communicative with native speakers of English, since they are used to deductive ways of reasoning with the liner patterns. It is true that standard varieties of English are not the only legitimate target language; indeed, target varieties are expanding (Higgins, 2003). However, students of the English Education Study Program - where the research is conducted — need to learn and hence be taught standard versions of English. The present study provides some input enhancement for ELT practices in Indonesian context, both in terms of process (i.e., tracing the language-learner language data (the term coined by Ellis, 1985) in pragmatic perspectives) and in terms of product (i.e., realizing nonnative 'varieties' in the acts of requesting in English.)

\section{REFERENCES}

Blum-Kulka, S. and E. Olshtain. 1984. Too Many Words: Length of Utterance and Pragmatic Failure. Studies in Second Language Acquisition 8: 47-61.

Brown, Penelope and Stephen C. Levinson. 1987. Politeness: Some Universals in Language Usage. Cambridge: Cambridge University Press.

Faerch, Claus and Gabriele Kasper. 1989. Internal and External Modification in Interlanguage Request Realization. In Shoshana Blum-Kulka., Julian House and Gabriele Kasper (Eds), Cross-Cultural Pragmatics: Request and Apologies. Norwood, New Jersey: Ablex Publishing Corporation.

Hassall, Tim. 2001. Modifying Requests in a Second Language. IRAL XXXIX (4): 259-283.

Higgins, Christina. 2003. Ownership of English in the Outer Circle: An alternative to the NS-NNS Dichotomy. TESOL Quarterly, Vol. 4: 615644.

Kaplan, Robert. 1996. "Cultural Thought Patterns in Intercultural Education." Language Learning 16: 1-20.

Merriam-Webster. 1983. Webster's Ninth New Collegiate Dictionary. Springfield, Massachusetts: Merriam-Webster Inc.

Searle, John R. 1969. Speech Acts: An Essay in the Philosophy of Language. New York: Cambridge University Press. 
Suh, Jae-Suk. 1999. Pragmatic Perception of Politeness in requests by Korean learners of English as a Second Language. IRAL, XXXVII (3): 195-213.

Thompson, Neil. 2003. Communication and Language: A handbook of Theory and Practice. New York: Palgrave Macmillan.

Wolfson, Nessa. 1989. Perspectives Sociolinguistics and TESOL. Boston, Massachusetts: Heinle \& Heinle Publishers.

Yu, Ming-Chung, 1999. Universalistic and Culture-specific Perspective on Variation in the Acquisition of Pragmatic Competence in a Second Language. Pragmatics 9(2): 281-312. 


\section{Appendix 1: DCT questionnaires}

\section{DCT Questionnaires}

\section{Instruction}

I would like to ask you to help me by answering the following questions concerning with requests. This is not a test so there is no "right" or "wrong" answer and you don't even have to write your name on it. Please give your answers sincerely as only this will guarantee the success of the investigation. Thank you very much for your help.

Imagine that you are in the following situations in an English speech community.

\section{Situation 1:}

You are preparing for a mid-term examination which is scheduled tomorrow. It's about 9 p.m. A new neighbor about your age whom you do not already know is playing music very loudly. So you cannot concentrate on your studying. You want this neighbor to turn down the music. What would you say to get the neighbor to do this favor?

\section{Situation 2:}

You are reading a book at a library. When you want to take notes you realize that you do not have a pen with you. A young person about your age whom you do not already know is sitting and reading a book next to you. You want to borrow a pen from this person.

What would you say to get this person to do this favor?

\section{Situation 3:}

You are very much interested in taking a course, but you notice that this course requires a prerequisite course. Although you do not meet this requirement and do not already know the lecturer, you want to ask the lecturer to allow you to take this course. 
What would you say to get the lecturer to grant you permission to take this course?

\section{Situation 4:}

You are on your way to a school building and your hands are both so full that you need someone to open the door for you. You notice that a person about forties whom you do not already know is standing nearby the door, and you see no other people near you. So you want to ask this person to open the door for you.

What would you say to get this person to do this favor for you?

\section{Situation 5:}

A friend of yours from out of town is paying you a visit. You are showing your friend around the campus and both of you would like to take a photo together to keep memory of this happy moment. So you want to ask a nearby student whom you do not already know to do you this favor.

What would you say to get this student to take your picture together?

\section{Situation 6:}

Your final exams are approaching and you find that the scheduled date of one subject is the same date as that of your brother's wedding. You cannot do both that day and you prefer to join this unforgettable moment of your family. So you want to ask your lecturer to rearrange another day especially for you to take this final exam.

What would you say to get your professor to allow you to take the exam on another day?

\section{Situation 7:}

You realize that you have left your textbook at home. The fellow student sitting next to you has the textbook open in front of you and is following the lesson. You want the fellow student to share the textbook.

What would you say to get him to share with you? 


\section{Situation 8:}

You did not come into the class last week because of sickness. It was the first meeting for this class last week, so you do not already know the lecturer. You did not get the handout that was distributed in the first meeting. The lecturer is approaching you now, so this is a good chance to talk to. You want to borrow the handout from the lecturer.

What would you say to get the lecturer to lend you the handout?

\section{Situation 9:}

You are asked to submit the final paper a week after the last meeting of this semester. You do not think that you can finish on the due day. You want the lecturer to extend the deadline.

What would you say to get this lecturer to extend the due day?

\section{Situation 10:}

You are preparing for upcoming final exams and find that one class is really difficult for you. A fellow student seems to understand the class much better than you. So you need to ask this fellow student to help you get ready for the exam.

What would you say to get this student to help you out?

\section{Situation 11:}

You are very much interested in sitting in one class taught by a lecturer whom you have studied with before. So you need to ask for the lecturer's permission to sit in.

What would you say to get this lecturer to allow you to sit in this class? 


\section{Situation 12:}

You missed one topic in a course you enrolled in, so you want to borrow a fellow student's notes to catch up with the rest of the class.

What would you say to get this student to lend you notes for the class you missed?

\section{Situation 13:}

You are in a mall to have a 'window shopping'. While walking along the dress showroom, you find a lot of nice T shirts with marked ' $30 \%$ discount'. You get interested in buying one. You want to buy one, but you get difficulty in finding the suitable size. A young (younger than you) shop assistant is approaching you. It is a good chance for you to ask the assistant to find the one that is suitable for you.

What would you say to ask the shop assistant to do this favor?

\section{Situation 14:}

You just arrive in a big city in which you do not recognize the places well. You want to see a person whose office in the city. You have the address written on the person's name card with you. Accidentally, you see a teenager walking on the path then you want to ask the teenager to tell you how get to the place.

What would you say to ask the teenager to help you out?

\section{Situation 15:}

You want to see a school principal. You need to ask someone to show you the principal's office. In the front gate, you see some students chatting. It is a good chance for you to ask one of them to help you see the principal. What would you say to one of the students to do this favor?

This is the end of questionnaires. 


\section{Appendix 2: Role-plays}

\section{Role Plays}

Instruction: Read the scenarios carefully and try to comprehend the contents and roles of the interlocutors in them. Demonstrate a dialogue of each scenario below with your fellow student.

\section{Scenario 1:}

You want to go home in a hurry after the class because of dropping off your father to station to leave for out of town. You will be late if you take a bus from the campus. Fortunately, you see a fellow student riding a motor cycle. It is a good chance for you to ask the fellow student to give a ride home.

\section{Scenario 2:}

You are in a class. The lecture is about to start. You realize that you do not have a pen with you. You want to borrow a pen from a fellow student who is sitting next to you.

\section{Scenario 3:}

You are preparing a final paper for your class. Your lecturer recommends you to go to library to find a book related to my paper topic. Now you are in a school library to look for the book. However, you have difficulty in finding the book, so you want the librarian whom you already know to help you out.

\section{Scenario 4:}

You are reading to prepare your final exams. A new neighbor about your age who stays next door in your apartment is playing music loudly. It is very hard for you to concentrate on your studying. You do not already know the neighbor because of newly moving to this apartment. You need to ask the neighbor to turn down the music.

\section{Scenario 5:}

You are in a downtown to find an office in which you are going to have a job interview. You need someone to help you find the place. Fortunately, you see a teenager walking along the path, so you approach the teenager and ask for this favor.

\section{Scenario 6:}


You are completing your final paper or skripsi. You want to see and consult with your advisor about the paper. You see the advisor coming to the office. It is a good chance for you to have a consultation.

\section{Scenario 7:}

There is a good movie during the weekend. You plan to go seeing the movie. You feel that will be more interesting if you go with your friend, so you ask your close friend to see the movie together with you.

\section{Scenario 8:}

You are in an office to apply a job. You want to be accepted by the manager in the vacant position. Now you are answering to the questions in the interview and convincing the manager of your capability.

\section{Scenario 9:}

You are in a shoe store. You plan to buy a pair of shoes. After noticing some of the shoes in the showroom, you get interested in a certain pair of shoes. Of course, you need to try on the shoes. You see the shop assistant and ask for doing this favor.

\section{Scenario 10:}

You are in a music store and want to buy a cassette. After you get the cassette that you would like to buy, you need to ask the shop assistant to let you try on listening to it. You already know the shop assistant, since you have been to this store for several times before. 